\title{
Evaluation on the Distribution of EGFR, KRAS and BRAF Genes and the Expression of PD-LI in Different Types of Lung Cancer
}

Rui Zhao

Shan Gao

Haiqi $\mathrm{He}$

Jia Zhang

Guangjian Zhang

Xiaopeng Wen (D)

Department of Thoracic Surgery, First Affiliated Hospital of Xi'an Jiaotong University, Xi'an, 7I006I, People's Republic of China
Correspondence: Xiaopeng Wen Department of Thoracic Surgery, First Affiliated Hospital of Xi'an Jiaotong University, \#277 West Yanta Road, Xi'an City, Shaanxi Province, 71006I, People's Republic of China

Email xiaopengwmd@163.com
Objective: To evaluate the distribution of high frequency mutant genes and the expression of PDL1 in different types of lung cancer.

Methods: This retrospective analysis was conducted on 330 patients who were diagnosed with primary lung cancer and treated in our hospital from October 2018 to October 2020. The patients were listed into non-small cell carcinoma group (101 cases), squamous carcinoma group (28 cases) and adenocarcinoma group (201 cases) according to their pathological results. The gene mutations were detected using EGFR, KRAS, and BRAF gene mutation detection kits, and the expression of PDL1 was detected by immunostaining. The mutation of EGFR, KRAS and BRAF genes and PDL1 expression in patients with different types of lung cancer were compared.

Results: The patients in the adenocarcinoma group had the highest incidence of EGFR gene mutation, the mutation rate of the gene whose mutation location was exon 18 was significantly higher, and the difference between each group was statistically significant $(P<0.05)$. The patients in the adenocarcinoma group had the highest incidence of KRAS gene mutation, the mutation rate of the gene whose mutation location was exon 2 was obviously the highest, exon 15 was the lowest, and the difference between each group was statistically significant $(P<0.05)$. There was no significant difference in the distribution of BRAF gene mutations among groups, and all mutations occurred on exon 15 , with no statistically significant difference between each group $(P>0.05)$. PD-L1 expression in NSCLC patients was significantly higher than that in other lung cancer patients $(P<0.05)$.

Conclusion: EGFR and KRAS genes showed obvious specific expressions in patients with different types of lung cancer and they were more common in patients with lung adenocarcinoma. Gene mutation and PDL1 expression are high in patients with lung adenocarcinoma.

Keywords: lung cancer, typing, gene mutation, PD-L1

\section{Introduction}

Lung cancer is one of the most common malignant tumor diseases, which has a serious impact on patients' life and living quality. With the changing of people's living habits and social development in recent years, the number of patients with lung cancer also shows a gradual increase. Early diagnosis and treatment of lung cancer patients would save their lives and effectively prolong their survival time. ${ }^{1,2}$ In recent years, with the deepening of biogenetics, it has been found in clinical practice that gene mutation technology and targeted therapy provide more possibilities for the treatment of lung cancer patients and provide a good method for 
individualized treatment. ${ }^{3}$ Targeted therapy for lung cancer patients has become an important treatment. Gene mutation detection can effectively guide patients to carry out targeted therapy, which is of great significance for saving patients' lives. Previous studies have generally assumed that the expression of different genes is independent, but in recent years more and more studies have pointed out that the various genes can coexist. PD-L1 (programmed death receptor - ligand 1) is the most important ligand of PD-1 (programmed death receptor-1) and plays a very important role in immune escape. Currently, PD-L1 is clinically used as one of the detection indicators of various malignant tumor cells and a relevant indicator of targeted therapy. ${ }^{4,5}$ The distribution of high frequency mutant genes and the expression of PDL1 in different types of lung cancer were analyzed in this study.

\section{Methods}

\section{Subjects}

The retrospective analysis was conducted on the 330 patients who were diagnosed with primary lung cancer and treated in our hospital from October 2018 to October 2020. The patients were divided into non-small cell carcinoma group (101 cases), squamous carcinoma group (28 cases) and adenocarcinoma group (201 cases) according to their pathological diagnosis results. There were 80 cases with tissue samples, 92 cases with surgical tissue samples, 84 cases with puncture tissue samples and 74 cases with fresh surgical tissue samples. The distribution of patients with TNM: 90 cases in stage-II, 196 cases in stage-III, and 44 cases in stage-IV. This study was approved by the Ethics Committee of the First Affiliated Hospital of Xi'an Jiaotong University. This study was conducted in accordance with the Declaration of Helsinki.

\section{Measurement}

\section{Gene Mutation Detection}

All the pathological tissue specimens or surgical specimens of patients were fixed with formaldehyde and embedded in paraffin. The paraffin tissues were amplified by fluorescence PCR on ABI 17500 instrument. A suitable amount of xylene was added to prevent the paraffin sections fixed by formaldehyde from dewaxing in a microcentrifuge tube and then eluting with ethanol. The tissue was dried at room temperature, and that ethanol was completely evaporated. A total of $180 \mathrm{~L}$ of buffer ATL tissue lysis buffer was added into the test tube, and 20L of protease $\mathrm{K}$ was added for shaking and blending, and the mixture was placed at $56{ }^{\circ} \mathrm{C}$ overnight. After all the samples are completely decomposed, tumor DNA is extracted by a kit, and then amplified, a PCR system is configured, a PCR reaction program is set, after the frozen reagent is thawed, the sample is vortex mixed actually and subjected to short centrifugation operation at $96{ }^{\circ} \mathrm{C}$ for 2 $\min , 10 \mathrm{~s}, 64{ }^{\circ} \mathrm{C}$ for $10 \mathrm{~s}$ and $72{ }^{\circ} \mathrm{C}$ for $30 \mathrm{~s}$, then subjected to short centrifugation at 1000RPM for electrophoresis detection, agarose gel is configured, $4 \mu \mathrm{L}$ of DNA amplification products are mixed for electrophoresis reaction, $160 \mathrm{v}$ for $35 \mathrm{~min}$, and then PCR products are purified to establish a whole genome library containing all target genes. Then the sequencing platform was used for ultradeep sequencing and data filtering, to analyze the bioinformatics data and count the gene mutations.

\section{PD-LI Detection}

Routinely dewaxing all tissue sections, HE staining, xylene dewaxing for $3 \mathrm{~min}$, and dehydration in accordance with the gradient of $100 \%, 80 \%$ and $70 \%$ of ethanol for 1 min, $1.5 \mathrm{~min}$ and $1.5 \mathrm{~min}$, respectively; using mobile water to wash for 40s, distilled water to treat for $20 \mathrm{~s}$, hematoxylin staining for $8 \mathrm{~min}$, and then using mobile water to wash the excess dye solution, eosin counterstaining for 1.5 min, mobile water for $30 \mathrm{~s}$, ethanol dehydration and xylene transparentizing, and finally using neutral gum to seal the sections. Next, the samples were put into 0.01 $\mathrm{mol} / \mathrm{L}$ citrate solution with $\mathrm{pH} 6.0$ by immunohistochemistry, and then fixed with antigen in a pressure cooker for 15 min. After cooling to room temperature, they were sequentially washed with PBS, exposed to antigen, treated with hydrogen peroxide, and incubated overnight with 1:100 dilution of anti-PD-1 monoclonal antibody and 1:120 dilution of PD-L1 polyclonal antibody. The incubation environment was maintained at $4{ }^{\circ} \mathrm{C}$. PBS solution was used as the blank control of primary antibody. After the biotinylated secondary antibody was incubated with HRP for $30 \mathrm{~min}$, DAB was developed for $3 \mathrm{~min}$. Then according to the color development, hematoxylin was redyed, identified with hydrochloric acid ethanol, and finally sealed with neutral glue. For staining observation, the region with the highest density of positive cells was selected in the low-meridian field, and the number of positive cells was recorded in the five random fields at high magnification. 


\section{Observation Index}

The distribution of EGFR (epidermal growth factor receptor), KRAS (mouse sarcoma virus carcinoma) and BRAF (mouse sarcoma viral oncogenic homolog) gene mutations and their mutation locations were compared among these groups. The positive expression of PD-L1 in these groups was compared.

\section{Statistical Analysis}

SPSS 22.0 was used for statistical analysis of the data, counting data were represented by "\%", and data between groups were tested by Chi-square. Measurement data was expressed as $(\mathrm{x} \pm \mathrm{s})$ and the comparison between each group was tested by using variance. The comparison result of $P<0.05$ indicated that the difference was statistically significant.

\section{Results}

\section{EGFR Gene Mutation}

The patients in the adenocarcinoma group had the highest incidence of EGFR gene mutation, the mutation rate of the gene whose mutation location was exon 18 was significantly higher, and the difference between each group was statistically significant $(P<0.05)$, as shown in Table 1 .

\section{KRAS Gene Mutation}

The patients in the adenocarcinoma group had the highest incidence of KRAS gene mutation, the mutation rate of the gene whose mutation location was exon 2 was obviously the highest, exon 15 was the lowest, and the difference between each group was statistically significant $(P<0.05)$, as shown in Table 2 .

\section{BRAF Gene Mutation}

There was no significant difference in the distribution of BRAF gene mutations detected among groups, and all mutations occurred on exon $15(P>0.05)$, as shown in Table 3.

\section{PD-LI Expression in Different Types of Lung Cancer}

In 330 cases, PD-L1 expression was negative in 19.69\% (65 cases), while weak, moderate and strong expression were observed in $80.31 \%$ (265 cases). PD-L1 expression in NSCLC patients was significantly higher than that in other lung cancer patients $(P<0.05)$ (Figure 1 and Table 4).

\section{Discussion}

Targeted therapy for lung cancer patients has become an important treatment. Gene mutation detection can effectively guide patients to carry out targeted therapy, which is of great significance for saving patients' lives. Previous studies have generally assumed that the expression of different genes is independent, but in recent years more and more studies have pointed out that the various genes can coexist. ${ }^{6}$ EGFR gene is the product of proto-oncogene C-erbB-1, a transmembrane protein and the first member of the epidermal growth factor receptor family. The mutations mainly occur in exons 18 21, and exon 19 and 21 mutations are more important, especially the positive exon 19 mutations which indicates better efficacy with molecular targeted drugs. ${ }^{7}$ Therefore, the detection of location of gene mutation in clinical practice can effectively predict the treatment effect of patients. ${ }^{8}$ The lung cancer patients carrying KRAS gene mutation are the most difficult kind to treat in clinical practice. Previous studies have found that this is mainly because KRAS gene mutation will develop drug resistance to EGFR, and its mutation will lead to increased activity in the downstream of tyrosine kinase signaling pathway, instead of the increased resistance due to the corresponding decrease in the inhibitory intervention of the upstream signaling pathway, thus the drug resistance will be increased. BRAF is also one of the most important proto-oncogenes in human beings. During the treatment of tumor patients, its mutation will lead to the continuous activation of downstream MEK-ERK

Table I Comparison of EGFR Gene Mutation of Different Types of Lung Cancer (\%)

\begin{tabular}{|l|l|l|l|l|l|}
\hline Group & EGFR I9 & EGFR I8 & EGFR 2I & EGFR 20 & Gene Mutation \\
\hline Adenocarcinoma group $(\mathrm{n}=20 \mathrm{I})$ & $4(1.99)$ & $76(37.8 \mathrm{I})$ & $28(13.93)$ & $5(2.49)$ & $113(56.22)$ \\
Non-small cell carcinoma group $(\mathrm{n}=10 \mathrm{I})$ & $16(15.84)$ & $4(3.96)$ & $17(16.83)$ & $6(5.94)$ & $43(42.57)$ \\
Squamous carcinoma group $(\mathrm{n}=28)$ & $6(2 \mathrm{I}) \mathrm{n3})$ & $\mathrm{I}(3.57)$ & $3(10.7 \mathrm{I})$ & $0(0.00)$ & $10(35.7 \mathrm{I})$ \\
$\chi^{2}$ & & & & & 8.815 \\
$\mathrm{P}$ & & & & & 0.012 \\
\hline
\end{tabular}

Notes: $\chi^{2}$ is chi-square test, and $P$ is the probability that the original hypothesis is true. EGFR is epidermal growth factor receptor. 
Table 2 Comparison of KRAS Gene Mutation of Different Types of Lung Cancer (\%)

\begin{tabular}{|l|l|l|l|l|}
\hline Group & KRAS E2 & KRAS E3 & KRAS EI5 & Gene Mutation \\
\hline Adenocarcinoma group $(\mathrm{n}=20 \mathrm{I})$ & $36(17.9 \mathrm{I})$ & $29(14.43)$ & $7(3.48)$ & $72(35.82)$ \\
Non-small cell carcinoma group $(\mathrm{n}=10 \mathrm{I})$ & $8(7.92)$ & $7(6.93)$ & $\mathrm{I}(0.99)$ & $16(15.84)$ \\
Squamous carcinoma group $(\mathrm{n}=28)$ & $2(7.14)$ & $2(7.14)$ & $0(0.00)$ & $4(14.29)$ \\
$\chi^{2}$ & & & & 16.815 \\
$P$ & & & & 0.000 \\
\hline
\end{tabular}

Notes: $\chi^{2}$ is chi-square test, and $P$ is the probability that the original hypothesis is true. KRAS is Mouse sarcoma virus carcinoma.

Table 3 Comparison of BRAF Gene Mutation of Different Types of Lung Cancer (\%)

\begin{tabular}{|l|l|}
\hline Group & BRAF EI5 \\
\hline Adenocarcinoma group $(\mathrm{n}=20 \mathrm{I})$ & $10(4.98)$ \\
Non-small cell carcinoma group $(\mathrm{n}=10 \mathrm{I})$ & $5(4.95)$ \\
Squamous carcinoma group $(\mathrm{n}=28)$ & $1(3.57)$ \\
$\chi^{2}$ & 0.302 \\
$P$ & 0.860 \\
\hline
\end{tabular}

Notes: $\chi^{2}$ is chi-square test, and $P$ is the probability that the original hypothesis is true. BRAF is mouse sarcomatosis Toxic carcinogenic homologue.

signaling pathway, thus promoting the growth, reproduction and metastasis of tumor cells, which is also the main reason for its drug resistance mechanism. The occurrence of drug resistance has limited the effect of drug therapy, and the mechanism of drug resistance, development of new drugs and research of preventing or delaying drug resistance have become the key problems needing to be solved. As a critical immunosuppression molecule, PD-1 has double-sided effects. On one hand, it can suppress the response of immune system to human cells and enhance the patient's tolerance ability by reducing the inflammatory response of $\mathrm{T}$ cells, on the other hand, it can prevent the immune system from killing cancer cells. PD-L1 is a receptor of PD-1, and its expression in cancer cells can inhibit the activity of tumor cells by combining PD-1 with effector T cells. ${ }^{9,10}$ The expression of PD-1 in tumor cells has obvious specificity and Cher has obvious regulatory effect on the immune mechanism. Therefore, it has been clinically considered as a research direction of targeted therapy and has achieved good results in the treatment of solid tumors, and its therapeutic implementation is diversified. Small-molecule inhibitors, monoclonal antibodies, bi-specific antibodies, antibody drug conjugate and cellular immunotherapy are all good methods for its treatment. $^{11,12}$

In this study, it was found that patients with different types of lung cancer had the highest incidence of EGFR gene mutation in the adenocarcinoma group, among which the gene mutation rate of exon 18 was significantly higher, while that of exon 19 and 21 was relatively few, indicating that the treatment of patients with adenocarcinoma was relatively difficult. According to KRAS gene mutation in patients in each group, the patients in adenocarcinoma group had the highest incidence of gene mutation. The gene mutation rate of exon 2 was significantly higher, while that of exon 15 was the least. It was also pointed out that patients with adenocarcinoma were more difficult to be treated, suggesting that they may have greater clinical resistance, which has a certain impact on the treatment effect. However, there was little difference in the distribution of BRAF gene mutations among the three groups,
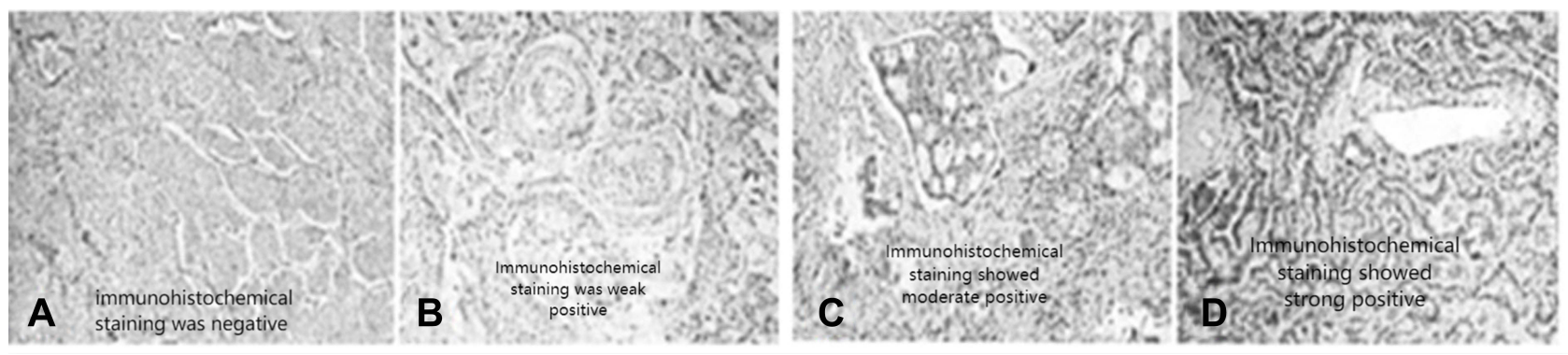

Figure I PD-LI respective immunohistochemical staining of different types of lung cancer-from left to right are negative, weak, moderate and strong expression. (A) Immunohistochemical staining was negative; (B) Immunohistochemical staining was weak positive; (C) Immunohistochemical staining showed moderate positive; (D) Immunohistochemical staining showed strong positive. 
Table 4 Expression Differences of PD-LI in Patients with Different Types of Lung Cancer [N, (\%)]

\begin{tabular}{|l|l|l|l|l|l|}
\hline PD-LI & $\begin{array}{l}\text { Adenocarcinoma Group } \\
(\mathbf{n = 2 0 I )}\end{array}$ & $\begin{array}{l}\text { Non-Small Cell Carcinoma } \\
\text { Group (n=10I) }\end{array}$ & $\begin{array}{l}\text { Squamous Carcinoma } \\
\text { Group (n=28) }\end{array}$ & $\chi^{\mathbf{2}}$ & $\boldsymbol{P}$ \\
\hline Negative & $47(23.39)$ & $15(14.85)$ & $3(10.71)$ & 25.383 & 0.000 \\
Weak & $48(23.89)$ & $21(20.79)$ & $10(35.71)$ & $9(32.14)$ \\
Moderate & $76(37.81)$ & $25(24.75)$ & $6(21.43)$ & \\
Strong & $30(14.93)$ & $40(39.60)$ & & \\
\hline
\end{tabular}

Notes: $\chi^{2}$ is chi-square test, and $P$ is the probability that the original hypothesis is true. PD-LI is Programmed death receptor-ligand I.

which may be related to the regional specificity of the patients included in this study, suggesting that relevant data should be continuously enriched in the follow-up studies to make the research results more accurate. The expression level of PD-L1 in patients with non-small cell lung cancer was significantly higher than those with other lung cancer, and the expression level of PD-L1 in adenocarcinoma patients was significantly higher than that in squamous cell carcinoma patients. The positive expression level of PD-L1 is closely related to the pathological state of tumor cells, which can make a more sensitive response to the presence of tumor, and effectively determine the invasion intensity of tumor cells in patients and their prognosis. It suggests that the therapeutic effect and prognosis of patients with non-small cell carcinoma may be worse after treatment, and clinical treatment should further explore effective treatment methods according to the patients' conditions.

In conclusion, EGFR and KRAS gene mutations have relatively distinct specificity expressions in patients with different types of lung cancer, and are more common in patients with lung adenocarcinoma, and EGFR gene mutations are less on exon 19 and 21 in patients with lung adenocarcinoma, suggesting that clinical treatment is more difficult in patients with adenocarcinoma, and patients are more prone to drug resistance. The PDL1 expressions in peripheral blood of patients with lung cancer are significantly different between patients with non-small cell carcinoma and patients with small cell carcinoma. Both the gene mutation and PDL1 expression are higher in the patients with lung adenocarcinoma, which suggests that the patients are more likely to have invasive cancer cells.

\section{Funding}

Basic Research Program of Natural Science of Shaanxi Province (2021JM-260); Xi'an Jiaotong University Basic Business Research Fee (xjh012020033).

\section{Disclosure}

The authors report no conflicts of interest in this work.

\section{References}

1. Arbour KC, Riely GJ. Systemic therapy for locally advanced and metastatic non-small cell lung cancer: a review. JAMA. 2019;322 (8):764-774. doi:10.1001/jama.2019.11058

2. Wu YL, Cheng Y, Zhou X, et al. Dacomitinib versus gefitinib as first-line treatment for patients with EGFR-mutation-positive non-small-cell lung cancer (ARCHER 1050): a randomised, open-label, Phase 3 trial. Lancet Oncol. 2017;18(11):1454-1466. doi:10.1016/S1470-2045(17)30608-3

3. Takeda M, Nakagawa K. First- and second-generation EGFR-TKIs are all replaced to osimertinib in chemo-naive EGFR mutation-positive non-small cell lung cancer? Int $J$ Mol Sci. 2019;20(1):146. doi:10.3390/ijms20010146

4. Gandara DR, Paul SM, Kowanetz M, et al. Blood-based tumor mutational burden as a predictor of clinical benefit in non-small-cell lung cancer patients treated with atezolizumab. Nat Med. 2018;24 (9):1441-1448. doi:10.1038/s41591-018-0134-3

5. Román M, Baraibar I, López I, et al. KRAS oncogene in non-small cell lung cancer: clinical perspectives on the treatment of an old target. Mol Cancer. 2018;17(1):33. doi:10.1186/s12943-018-0789-x

6. Yoneda K, Imanishi N, Ichiki Y, Tanaka F. Treatment of non-small cell lung cancer with EGFR-mutations. J UOEH. 2019;41 (2):153-163. doi:10.7888/juoeh.41.153

7. Jiang C, Lin X, Zhao Z. Applications of CRISPR/Cas9 technology in the treatment of lung cancer. Trends Mol Med. 2019;25 (11):1039-1049. doi:10.1016/j.molmed.2019.07.007

8. Hsu YC, Chang YH, Chang GC, et al. Tumor mutation burden and recurrent tumors in hereditary lung cancer. Cancer Med. 2019;8 (5):2179-2187. doi:10.1002/cam4.2120

9. Zhao ZR, Lin YB, Ng CSH, et al. Mutation profile of resected EGFR-mutated lung adenocarcinoma by next-generation sequencing. Oncologist. 2019;24(10):1368-1374. doi:10.1634/theoncologist.2018-0567

10. Pillai RN, Behera M, Berry LD, et al. HER2 mutations in lung adenocarcinomas: a report from the lung cancer mutation consortium. Cancer. 2017;123(21):4099-4105. doi:10.1002/ cncr.30869

11. Ricordel C, Lespagnol A, Llamas-Gutierrez F, et al. Mutational landscape of DDR2 gene in lung squamous cell carcinoma using next-generation sequencing. Clin Lung Cancer. 2018;19(2):163169.e4. doi:10.1016/j.cllc.2017.10.006

12. Fathi Z, Mousavi SAJ, Roudi R, Ghazi F, Deb S. Distribution of KRAS, DDR2, and TP53 gene mutations in lung cancer: an analysis of Iranian patients. PLoS One. 2018;13(7):e0200633. doi:10.1371/ journal.pone. 0200633 
International Journal of General Medicine

Dovepress

\section{Publish your work in this journal}

The International Journal of General Medicine is an international, peer-reviewed open-access journal that focuses on general and internal medicine, pathogenesis, epidemiology, diagnosis, monitoring and treatment protocols. The journal is characterized by the rapid reporting of reviews, original research and clinical studies across all disease areas. The manuscript management system is completely online and includes a very quick and fair peer-review system, which is all easy to use. Visit http://www.dovepress.com/ testimonials.php to read real quotes from published authors.

Submit your manuscript here: https://www.dovepress.com/international-journal-of-general-medicine-journal 